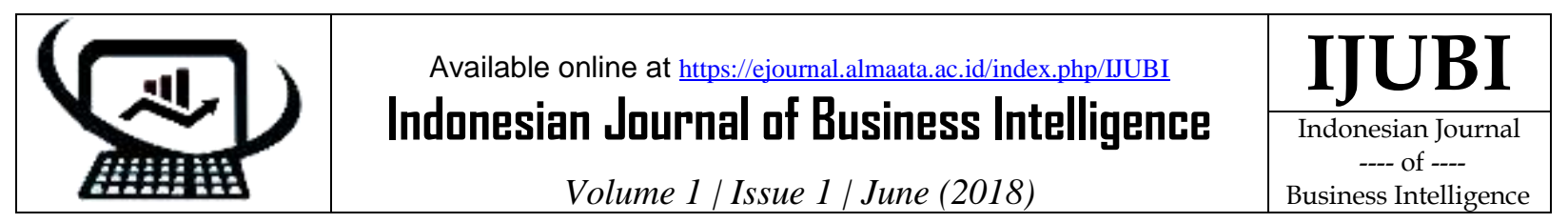

\title{
AUDIT INFRASTRUKTUR TEKNOLOGI INFORMASI BERBASIS ITIL V.3 DOMAIN SERVICE TRANSITION PADA SIPMAS LPPM IT TELKOM PURWOKERTO
}

Rahmat Hidayat ${ }^{1}$, Agung Laksana², Eben Haezer Siregar ${ }^{3}$, Handy Nur Prabowo ${ }^{4}$, Egriva Kristoper Pinem ${ }^{5}$, Septian Anggoro ${ }^{6}$

123456Program Studi S1 Sistem Informasi, Fakultas Teknologi Industri dan Informatika, Institut Teknologi

Telkom Purwokerto

${ }^{1} 17103059 @$ ittelkom-pwt.ac.id, ${ }^{2} 17103064 @$ ittelkom-pwt.ac.id, ${ }^{3} 17103048 @$ ittelkom-pwt.ac.id,

417103052@ittelkom-pwt.ac.id, ${ }^{5} 17103069 @$ ittelkom-pwt.ac.id, ${ }^{6} 17103040 @$ ittelkom-pwt.ac.id

J1. D. I. Panjaitan No. 128, Purwokerto

Keywords:

ITIL V 3, Audit, Service Transition, SIPMAS, Maturity Level.

\section{Kata Kunci:}

ITIL V 3, Audit, Service Transition, SIPMAS, Maturity Level.

\section{Pendahuluan}

Institut Teknologi Telkom Purwokerto merupakan saalah satu universitas di purwokerto. Institut Teknologi Telkom sendiri memiliki visi untuk menjadi perguruan tinggi yang unggul dalam pengembangan sains, teknologi dan teknik berbasis teknologi telematika dan membentuk insan yang 39 "Rahmat Hidayat"
Institut Teknologi Telkom Purwokerto as one of the education providers in Indonesia. To support academic operations regarding community activities, Institut Teknologi Telkom Purwokerto has the support of an academic information system managed by LPPM IT Telkom Purwokerto. SIPMAS itself is currently in the process of upgrading so there needs to be supervision that must be done so that it does not need to go far to improve the quality of ongoing SIPMAS. For this reason, the maturity level of the SIPMAS is required by conducting an audit using the ITIL V.3 standard Transition domain of services related to Release \& deployment Management, Service Validation \& testing, Change Management, and Transitional Planning \& Support. The results of the measurement of the maturity level of the SIPMAS IT Telkom Purwokerto are determined at level 3 defined. Recommendations are given so that the maturity level rises to level 5 .

Institut Teknologi Telkom Purwokerto merupakan salah satu penyelenggara pendidikan di Indonesia. Untuk mendukung operasional akademik mengenai kegiatan pengabdian masyarakat Institut Teknologi Telkom Purwokerto memiliki layanan sistem informasi akademik SIPMAS yang dikelola oleh LPPM IT Telkom Purwokerto. SIPMAS sendiri sedang dalam peningkatan sistem (upgrading) sehingga menuntut adanya pengawasan yang harus dilakukan agar tidak mengganggu bahkan menurunkan kualitas SIPMAS yang sedang berjalan. Untuk itu diperlukan nilai kematangan dari sipmas yang dilakukan dengan melakukan audit menggunakan standar ITIL V.3 domain Service transition khususnya yang terkait dengan Release \& Deployment Management, Service Validation \& testing, Change Management, dan Transition Planing \& Support. Hasil pengukuran tingkat kematangan dari sipmas IT Telkom Purwokerto sendiri secara keseluruhan berada pada level 3 yaitu defined. Rekomendasi diberikan agar level kematangan naik ke level 5.

berkarakter. Karena itu Institut Teknologi Telkom harus memberikan sarana maupun prasarana yang baik bagi keluarga Institut Teknologi Telkom sendiri dari sisi teknologi, management, dan fasilitas sehingga menjadi perguruan tinggi yang baik. Oleh sebab itu Institut Teknologi Telkom memerlukan adanya evaluasi kematangan, salah satu cara yang dilakukan 
untuk menilai kematangan suatu perguruan tinggi adalah dengan melakukan audit.

SIPMAS merupakan sebuah sistem infromasi yang digunakan oleh para dosen dalam bidang pengabdian masyarakat. Sipmas sendiri di kelola oleh direktorat sistem infromasi (SISFO). Selain adanya pengembangan sistem (upgrading) fasilitas teknologi yang dilakukan oleh sisfo menuntut adanya pengawasan yang harus dilakukan agar tidak mengganggu bahkan menurunkan kualitas Sipmas yang sedang berjalan.Karena itu Sipmas memerlukan evaluasi sebagai sistem informasi pengabdian masyarakat di Institut Teknologi Telkom Purowokerto. Bentuk evaluasi dilakukan dengan kegiatan audit untuk mengetahui faktor-faktor yang harus dilakukan atau diperbaiki untuk meningkatkan kinerja SIPMAS kedepan.

Standar yang digunakan dalam proses audit Sipmas adalah Information Technology Infrastructure Library (ITIL) V3 yang fokus pada best practice tata kelola teknologi informasi khususnya dalam layanan IT Service Management. Menurut buku panduan OGC (Of Government Commerce) mengenai penggunaan ITIL yang digunakan oleh banyak perusahaan internasional khususnya pada IT service Management sebagai standar audit sesuai untuk mendukung direktorat sistem informasi yang menjalankan kegiatan operasional dalam rangka mengelola Simmas sebagai pusat sistem informasi pengabdian masyarakat di Institute Teknologi Telkom Purwokerto. Domain pada ITIL yang digunakan dan dijadikan sebagai standar pengukuran audit yaitu domain Service Transition [1].

\section{Landasan Teori}

\section{ITIL V3}

ITIL (Information Technology Infrastructure Library) merupakan suatu kerangka kerja atau framework umum yang menggambarkan best practice pada IT service management. Dalam ITIL terdapat kerangka kerja yang digunakan untuk pengelolaan dan pengendalian layanan IT yang fokus pada pengukuran berkelanjutan dan peningkatan kualitas layanan IT[1].Tujuan dari kerangka kerja ITIL ini adalah untuk meningkatkan efisiensi operasional TI dan kualitas layanan pelanggan karena hanya berfokus pada layanan pelanggan dan sama sekali tidak termasuk proses menyelaraskan strategi perusahaan dengan strategi TI yang dikembangkan. ITIL V3 terdiri

40 "Rahmat Hidayat" dari 4 service yaitu service strategy, service design, service transition, dan service operation.

\section{Audit Teknologi Informasi}

Audit Teknologi Infromasi merupakan salah satu bentuk audit operasional yang bertujuan untuk meningkatkan tata kelola TI. Audit ini dilakukan untuk mengevaluasi unit sistem informasi, pengelolaan sumberdaya informasi pengembangan sistem aplikasi dan kemudian menerapkan sistem dan mengevaluasinya. Audit IT perlu dilakukan dalam rangka meningkatkan efektivitas dan efisiensi dalam perusahaan. Alasan perusahaan melakukan audit teknologi informasi adalah untuk menghindari resiko seperti kehilangan data, risiko kebocoran data, penyalahgunaan komputer,kerugian akibat kesalahan perhitungan dari perhitungan dan nilai yang tinggi dari investasi perangkat keras dan perangkat lunak [2].

\section{Service Transition}

Service transition merupakan sevice yang berkaitan dengan manajemen perubahan dan, lebih khusus, dengan fokus pada pengenalan layanan baru Service transition sendiri memiliki memiliki 7 proses, yaitu knowledge management, service asset and configuration management, Change evaluation, release and deployment management, service validation and testing, change management, dan transition planning and support [3].

Didalam domain ini terdapat lima proses utama dalam tahapan service transition, yaitu :

Change Management yaitu proses mengontrol siklus hidup semua perubahan-perubahan dalam layanan TI, memastikan perubahan benar-benar memberi keuntungan bagi bisnis organisasi dengan menekan kemungkinan gangguan terhadap layanan TI semaksimal mungkin.

Service asset and configuration management yaitu proses mengelola informasi tentang configuration items (CI) dan hubungan antar CI yang dibutuhkan untuk penyediaan sebuah layanan TI.

Release and deployment management yaitu proses merencanakan, membangun/ menyiapkan dan mengontrol produk-produk perubahan (release) untuk diuji dan diimplementasikan dilingkungan kerja sebenarnya. Proses ini memastikan komponen-komponen dari produk perubahan sudah benar dan sukses diterapkan di proses bisnis dan lingkungan kerja sebenarnya. 
Knowledge management yaitu proses mengumpulkan, menganalisis, menyimpan dan menyebarkan pengetahuan dan informasi dalam sebuah organisasi.

Transition planning and support (projekct management) yaitu proses merencanakan dan menggoordinasi sumber daya TI untuk mengimplementasikan sebuah produk perubahan besar dalam perkiraan biaya, waktu dan kualitas tertentu.

\section{Maturity Level}

Analisis kondisi kematangan diukur dengan menggunakan kerangka COBIT. Pengukuran kematangan dilakukan dengan menggunakan COBIT karena kerangka ITIL tidak memiliki panduan untuk mengukur tingkat kematangan. Metode pengukuran tingkat kematangan pada ITIL menggunakan Maturity Level. Dalam Maturuty level terdapat lima tingkat kematangan pada ITIL, yaitu: Initial, Repeatable, Defined, Managed, dan Optimized. Lima tingkatan maturity level tersebut memiliki karakteristik sendiri-sendiri. Level tingkat kematangan yang terdapat dalam maturity level dapat dilihat pada gambar dibawah [1].

\section{CMMI Staged Represenation- Maturity Levels}

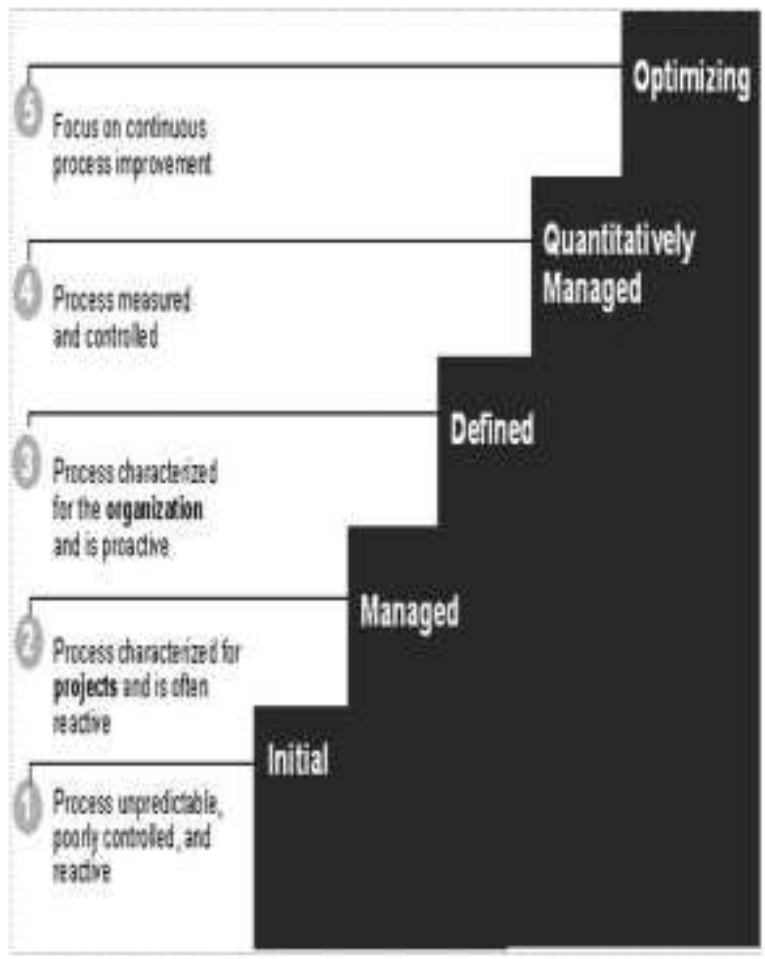

Gambar 1. Maturity level

\section{Metode}

Untuk penelitian kali ini metodologi penelitian yang digunakan adalah metode Action research. Metodologi penelitian membahas tahapan pelaksanaan audit. Ada beberapa tahap yang dilakukan dalam audit layanan TI. Tahap pertama adalah planning(Perencanaan), pada tahap ini yang dilakukan yaitu melakukan perumusan masalah, tujuan dan batasan masalah. Selain itu,pada tahapan ini study literature juga dilakukan. Tahap kedua adalah acting, pada tahapan ini yang dilakukanan adalah penentuan domain. Untuk domain sendiri menggunakan service transition. Tahap ketiga adalah observing, pada tahapan ini yang dilakukan adalah dengan melakukan pengumpulan data. Dalam penelitian ini pengumpulan data dilakukan dengan cara survey dengan menggunakan kuesioner. Pada tahap ke empat adalah pengolahan dan analisis, pada tahap ini yang dilakukan adalah perhitungan dan menentukan tingkat kematangan dari sipmas domain service transition. Pada tahap kelima adalah rekomendasi. Rekomendasi yang diberikan bertujuan untuk mencapai target yang diinginkan.

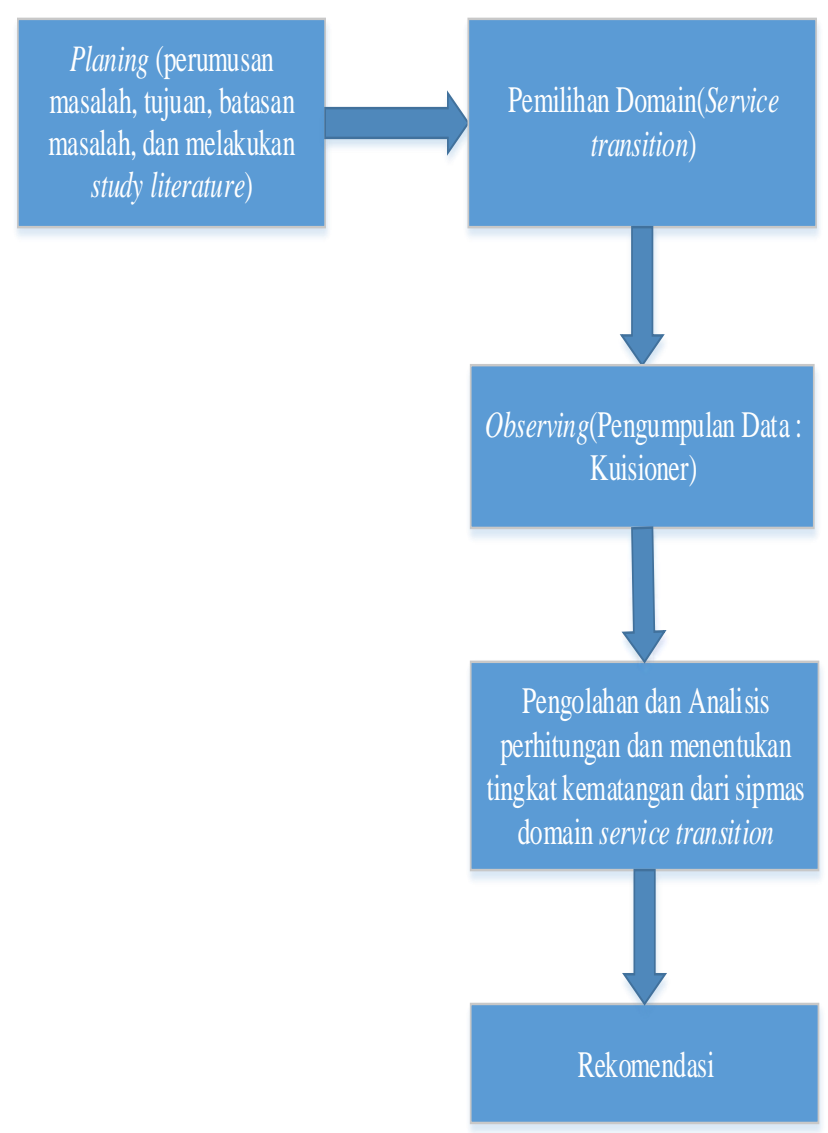

Gambar 2. Metodologi Penelitian 


\section{Hasil dan Pembahasan}

\section{Analisys Tingkat Kematangan Saat Ini}

Penilaian tingkat kematangan ini terdiri beberapa level mulai dari 1-5 yang disebut dengan maturity level. Penilaian tingkat kematangan dilakukan dengan mencari nilai rata-rata pada setiap aktivitas dan subdomain dari acuan hasil kuisioner yang sudah dilakukan. Kriteria penilaian maturity level bisa dilihat pada table dibawah ini.

\begin{tabular}{cc}
\hline Maturity level & keteranagan \\
\hline 0 & Non existent \\
\hline 1 & Initial \\
\hline 2 & Repeatable \\
\hline 3 & Define \\
\hline 4 & Managed \\
\hline 5 & Optimizing \\
\hline
\end{tabular}

Table 1. Maturity level

Dalam melakukan pengukuran maturity level, digunakan kuisioner sebagai metode pengumpulan data yang akan memiliki nilai indeks dari masing-masing kriteria pada pengukuran yang dilakukan. Pengukuran dilakukan dengan menggunakan rumus sebagai berikut :

$$
\text { indeks }=\frac{\sum(\text { Total Nilai Jawaban }}{\text { (Jumlah Soal x Jumlah Responden })}
$$

Adapun hasil penilaian tingkat kematangan (Maturity Level) dari ke empat subdomain pada domain Service Transition adalah sebagai berikut.

\begin{tabular}{|c|c|c|c|}
\hline Subdomain & Nilai & Level & Keterangan \\
\hline $\begin{array}{ll}\text { Release } & \mathcal{E} \\
\text { Deployment } & \\
\text { Management } & \end{array}$ & 3.46 & 3 & Defined \\
\hline $\begin{array}{l}\text { Service Validation } \\
\text { E testing }\end{array}$ & 3.73 & 3 & Defined \\
\hline $\begin{array}{l}\text { Change } \\
\text { Management }\end{array}$ & 3.25 & 3 & Defined \\
\hline $\begin{array}{l}\text { Transition } \\
\text { Planing } \\
\text { Support }\end{array}$ & 3.4 & 3 & Defined \\
\hline
\end{tabular}

\section{Table 2. Hasil Penilaian Maturity Level}

Pada tabel di atas dijelaskan mengenai tingkat kematangan dari Sipmas, pada saat ini tingkat kematangan dari Sipmas berada pada level 3 atau pada level Defined.

\section{Gap analisys}

Setelah diketahui tingkat kematangan dari sipmas, selanjutnya menentukan tingkat target kematangan sehingga menyebabkan kesenjangan seperti yang ditunjukkan pada tabel di bawah ini.

\begin{tabular}{|c|c|c|c|}
\hline \multirow[t]{2}{*}{ Subdomain } & \multicolumn{3}{|c|}{ Maturity Level } \\
\hline & Current & Target & Gap \\
\hline $\begin{array}{l}\text { Release } \mathcal{E} \\
\text { Deployment } \\
\text { Management }\end{array}$ & 3.46 & 5 & 1,54 \\
\hline $\begin{array}{l}\text { Service Validation } \\
\text { E testing }\end{array}$ & 3.73 & 5 & 1.27 \\
\hline $\begin{array}{l}\text { Change } \\
\text { Management }\end{array}$ & 3.25 & 5 & 1.75 \\
\hline $\begin{array}{l}\text { Transition } \\
\text { Planing } \\
\text { Support }\end{array}$ & 3.4 & 5 & 1.6 \\
\hline
\end{tabular}

Table 3. Gap Rate

Pada Tabel di atas terlihat bahwa ada kesenjangan di setiap subdomain pada service transition. Dengan adanya kesenjanga sehingga rekomendasi yang diperlukan untuk perbaikan dan peningkatan tingkat kematangan untuk mencapai target yang diharapkan. Pada Gambar di bawah ini dapat dilihat sebuah ilustrasi dari tingkat kematangan saat ini dan yang diharapkan.

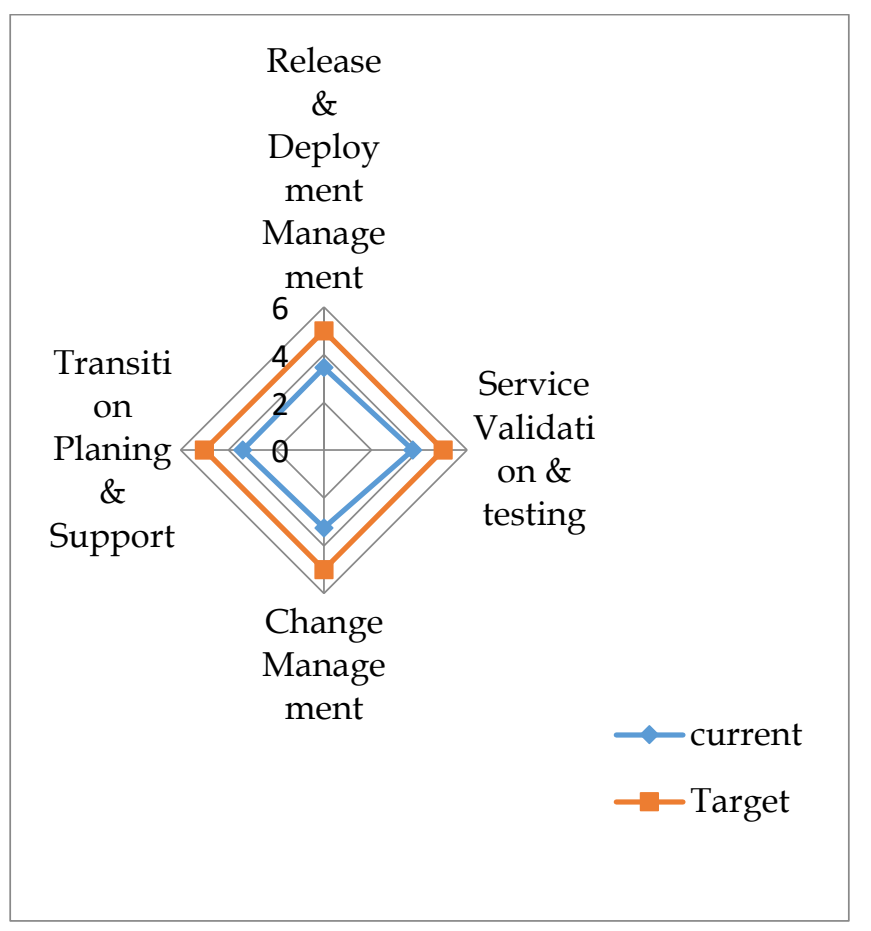

Gambar 3. Hasil dan Ilustrasi Tingkat Kematangan Sekarang dan Target 
Pada Gambar 4 kita bisa melihat grafik dari tingkat kematangan saat ini dan tingkat kematangan yang diharapkan.

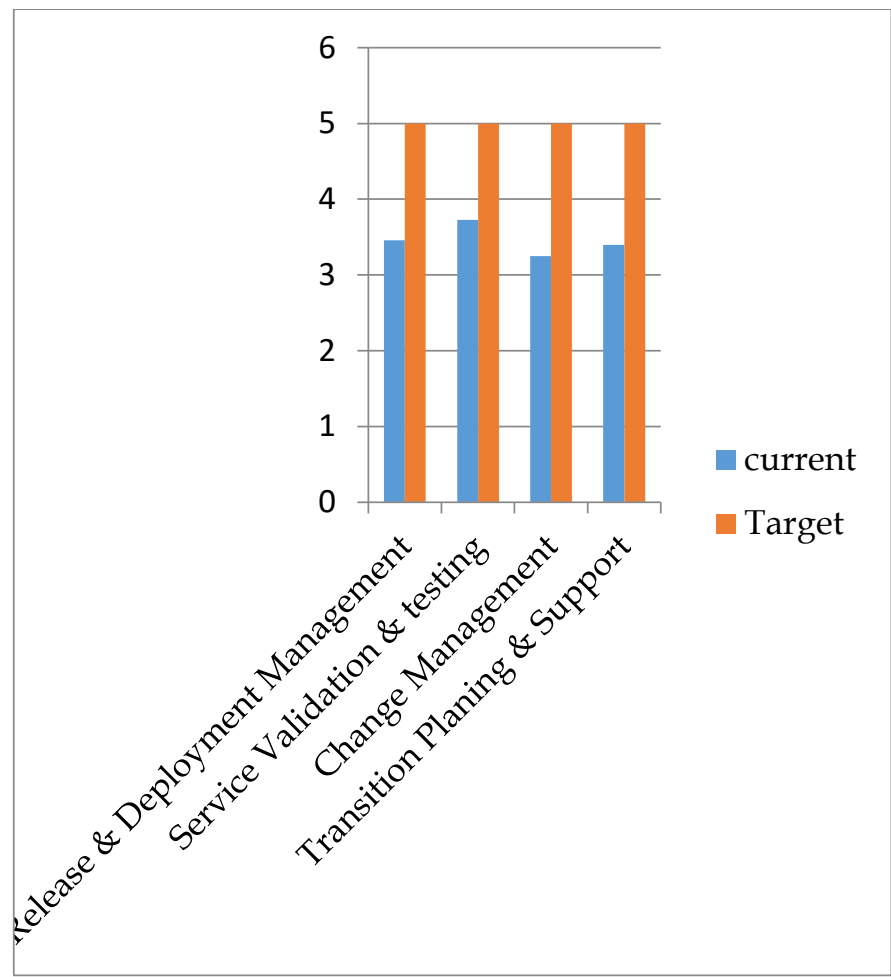

Gambar 4. Grafik Tingkat Kematangan Sekarang dan Target

\section{Rekomendasi}

\section{Release $\mathcal{E}$ deployment management}

Dari hasil pengukuran tingkat kematangan dari subdomain release and deployment management ini berada pada level 3 (defined) yaitu prosedur telah distandarisasikan, didokumentasikan, serta dikomunikasikan melalui pelatihan. Namun, implementasinya diserahkan pada setiap individu, sehingga kemungkinan besar penyimpangan tidak dapat dideteksi. Permasalahan didalam system ini belum mencapai pada skala 5 dikarenakan layanan yang dimiliki belum ada perbaikan atau upgrade pada sistem yang berkelanjutan. Dari hasil penelitian ini SIPMAS belum memenuhi standar dari Release and Deployment Management dikarenakan belum adanya panduan dalam deployment testing. Berdasarkan hasil audit maka rekomendasi yang harus dilakukan pada SIPMAS sesuai dengan release deployment management yaitu dengan membuat dokumen pedoman yang mengatur tentang release dan deployment.

\section{Service Validation \& Testing}

Dari hasil pengukuran tingkat kematangan dari subdomain service validation $\mathcal{E}$ testing ini berada pada level 3 (defined) yaitu prosedur telah distandarisasikan, didokumentasikan, serta dikomunikasikan melalui pelatihan. Namun, implementasinya diserahkan pada setiap individu, sehingga kemungkinan besar penyimpangan tidak dapat dideteksi. Permasalahan didalam system ini belum mencapai pada skala 5 dikarenakan layanan yang dimiliki belum ada perbaikan atau upgrade pada sistem yang berkelanjutan. Dari hasil penelitian ini SIPMAS belum memenuhi standar dari service validation $\mathcal{E}$ testing dikarenakan belum adanya panduan dalam melakukan validation $\mathcal{E}$ testing. Berdasarkan hasil audit maka rekomendasi yang harus dilakukan pada SIPMAS sesuai dengan service validation $\mathcal{E}$ testing yaitu dengan dibuatkannya standar operasional prosedur yang secara formal digunakan untuk setiap proses dalam validasi dan pengujian system.

\section{Change Management}

Dari hasil pengukuran tingkat kematangan dari subdomain change management ini berada pada level 3 (defined) yaitu prosedur telah distandarisasikan, didokumentasikan, serta dikomunikasikan melalui pelatihan. Namun, implementasinya diserahkan pada setiap individu, sehingga kemungkinan besar penyimpangan tidak dapat dideteksi. Permasalahan didalam system ini belum mencapai pada skala 5 dikarenakan layanan yang dimiliki belum ada perbaikan atau upgrade pada sistem yang berkelanjutan. Dari hasil penelitian ini SIPMAS belum memenuhi standard dari change management dikarenakan belum adanya dokumentasi yang mencatat setiap tahap dalam perubahan dan Belum ada assessment dampak untuk memperhatikan risiko \& dampak yang ditimbulkan dari perubahan. Berdasarkan hasil audit maka rekomendasi yang harus dilakukan pada SIPMAS sesuai dengan Change Management yaitu dengan mencatat setiap yang terjadi pada perubahan dicatat dalam dokumentasi sesuai pedoman tata kelola dan dibuatkan data progress dari target dan pencapaian setiap perubahan. 


\section{Transiton Planing \& Suport}

Dari hasil pengukuran tingkat kematangan dari subdomain transition planning $\mathcal{E}$ support ini berada pada level 3 (defined) yaitu prosedur telah distandarisasikan, didokumentasikan, serta dikomunikasikan melalui pelatihan. Namun, implementasinya diserahkan pada setiap individu, sehingga kemungkinan besar penyimpangan tidak dapat dideteksi. Permasalahan didalam system ini belum mencapai pada skala 5 dikarenakan layanan yang dimiliki belum ada perbaikan atau upgrade pada sistem yang berkelanjutan. Dari hasil penelitian ini SIPMAS belum memenuhi standard dari transition planning $\mathcal{E}$ support dikarenakan tidak semua proses planning \& support perubahan dalam SIPMAS memiliki panduan. Berdasarkan hasil audit maka rekomendasi yang harus dilakukan pada SIPMAS sesuai dengan Transition planning $\mathcal{E}$ support yaitu dengan dibuatkannya standar operasional prosedur dalam setiap planning \& support perubahan yang terjadi dalam SIPMAS.

\section{Kesimpulan dan Saran}

Berdasarkn hasil audit tingkat kematangan dari SIPMAS domain service transition khususnya tentang Release \& Deployment Management, Service Validation $\mathcal{E}$ testing, Change Management, dan Transition Planing $\mathcal{E}$ Support tingkat kematangan dari SIPMAS sendiri berada pada level 3 (Defined). Untuk meningkatkan tingkat kematangan dari SIPMAS menjadi level 5(Optimizing) sendiri telah diberikan beberapa rekomendasi yang nantinya diharapkan dapat meningkatkan tingkat kematangan dari SIPMAS itu sendiri.

Adapun saran yang diajukan untuk penelitian yang selanjutnya adalah sebagai berikut: Dilakukan proses audit dengan menggunakan domain service ITIL yang berbeda, yaitu service strategy, service design, dan service operation; Dilakukan proses audit dengan studi kasus layanan yang ada di Institut Teknologi Telkom yang dikelola SISFO yang lain.

\section{Referensi}

[1] Lesmana, Hendra P, dkk. 2015." Audit Infrastruktur Teknologi Informasi Berbasis ITIL V.3 Domain Service Operation pada FMS Departemen Engineering PT. Grand
Indonesia". e-Proceeding of Engineering : Vol.2, No.2. Page 6084.

[2] Ni Putu Sri Merta Suryani, dkk. 2017." Audit of Governance Information Technology Services Using ITIL v3 Focuseson Service Operation Domain in Institution $X^{\prime \prime}$. International Journal of Engineering and Emerging Technology : Vol. 2, No. 2. Page 9195.

[3] Sugiarto, Charlie, dkk. 2015." Analisis dan Perancangan ITSM Domain Service Transition pada Layanan Akademik Institut Pemerintahan Dalam Negeri (IPDN) dengan Menggunakan Framework ITIL versi 3". eProceeding of Engineering: Vol.2, No.2. Page 5750.

[4] Ananda,Vera, dkk. 2015."Perancangan Service Transition pada Layanan IT pt.xyz dengan Menggunakan Framework ITIL versi 3". e-Proceeding of Engineering : Vol.2, No.2. Page 5540.

[5] Wardani. Luki Aisha Kusuma, dkk. 2016." Perancangan Tata Kelola Layanan Teknologi Informasi Menggunakan ITIL versi 3 Domain Service Transition Dan Service Operation Di Pemerintah Kota Bandung". Journal of Information Systems Engineering and Business Intelligence : Vol. 2, No. 2. Hlm. 8187.

[6] Pribadi. Rizal Dwiwahyu, dkk. 2017."Pengukuran Tingkat Kematangan Teknologi Informasi Berbasis ITIL v.3 di Universitas Jenderal Achmad Yani". Jurnal Ilmiah Teknologi Informasi Terapan Volume IV, No 1. Hlm. 11-17.

[7] Bahtiar. Mashuda, dkk. 2018." Evaluasi Tingkat Kematangan Sistem Informasi Manajemen Rumah Sakit Menggunakan ITIL (Information Technology Structure Library) Versi 3 (Studi Pada : Rumah Sakit Umum Universitas Muhammadiyah Malang)". Jurnal Pengembangan Teknologi Informasi dan Ilmu Komputer : Vol. 2, No. 11. Hlm. 4525-4531.

[8] Sakinah, Faroh dan Bambang Setiawan. 2014."Indeks Penilaian Kematangan (Maturity) Manajemen Keamanan Layanan TI". Jurnal Teknik Pomits : Vol. 3, No. 2. Hlm. A-222 - A-227 